\title{
Scientific Writing Requirements in University Courses according to a Survey Carried out at "A. Xhuvani" University, Elbasan
}

\author{
Ema Kristo \\ "Aleksander Xhuvani" Elbasan \\ Faculty of Human Sciences \\ Tel:00355692054615, ema_kristo@yahoo.com
}

Doi:10.5901/jesr.2014.v4n2p443

\section{Abstract}

Besides major scientific studies such as bachelor, master and PhD studies, short types of texts such as note-taking, protocols, summaries of basic information, essays and course papers, play an important role in the process of scientific writing. These are preparatory texts in the process of scientific writing, which are often forgotten or not treated when talking about scientific writing. The aim of this article is to point out the role played by these types of texts throughout university studies. Through the evaluation and interpretation of a survey results made at University of Elbasan, some scientific writing requirements are outlined and it is stressed the importance of developing a methodology concerning scientific writing as well.

Keyword: scientific study, records, protocols, course paper, methodology of writing.

\section{Introduction}

Recently, it has been made clearer with every passing day, that the acquired knowledge, abilities and skills related to scientific writing, are essential/substantial prerequisites for a successful study. The fact, that the majority of the students do not master sufficiently these abilities and skills, has already been proved by the reports gathered from teaching practice/school experience at universities, and from the many empirical studies in this field as well. This study has a different view. It does not scrutinize the difficulties of the students related to writing academic texts through student questionnaires in various disciplines, as done previously in some studies; this study does not see the problem through the eyes of the students but through the eyes of the university lecturers.

The present study/research - a teacher survey at "A. Xhuvani" University, Elbasan - is focused on different types of written scientific assignments that the students have to prepare within respective disciplines/courses and on the role that they play for students' academic formation. The most important results of this survey will be presented in this study. They allow us to find the main issues of writing in various disciplines/courses and they give a modest contribution to the scientific formation of the students in-depth.

\section{The survey}

For the survey, a questionnaire was prepared, which focused on some practical types of scientific writings, which the students face with in most of their courses. Four types of texts were chosen; each of them belongs to a specific function in terms of knowledge acquisition and assimilation. Within relevant disciplines/courses they play special roles in scientific preparation. It is about note-taking, protocols, summaries and course papers. The lecturers were asked for the frequency of using these types of texts, and their functions in students' studies as well. At the same time the lecturers were asked for the way they assessed and evaluated their students' writing.

The prepared questionnaire was given to 120 lecturers of UE, out of which more than half (78 persons) replied to us. The assessment and evaluation was conducted in various courses/disciplines in four faculties. Fig. 1 gives a picture on these groups and their relevant replies. It was noticed that a great number of lecturers accepted the questionnaire. Their personal notes in the questionnaire highlight the importance given to scientific writing.

This research/study has great importance [....] (Methodology and Teaching Department) 
I have been teaching 'Scientific Writing' for six years, and I have noticed that a lot of students have difficulties in linguistic/language way of expressing themselves, which shows that the students have little knowledge about the right form of scientific writings (English and German Languages Department)

\section{The results of the survey/ Survey results}

\subsection{Note-taking}

Concerning note-taking, the lecturers have been asked that how many times the students take down notes during their lectures and seminars, and if the students are given instructions how to take down notes.

The survey results that most of the lecturers notice that their students take down notes regularly while lecturing. Differences among various disciplines are relatively small/minor. $92 \%$ of the students at the Human Sciences Faculty (FSHH), 90\% of the students of Natural Sciences Faculty (FSHN), 89\% of the students of Faculty of Economy (FE), reply 'regularly' (alongside 'rarely' and 'never'; and a little bit less the students of the Faculty of Education Sciences (FSHE) with $83 \%$. (See fig. 1)

Fig.1: Note-taking during the lectures.

Tab 1

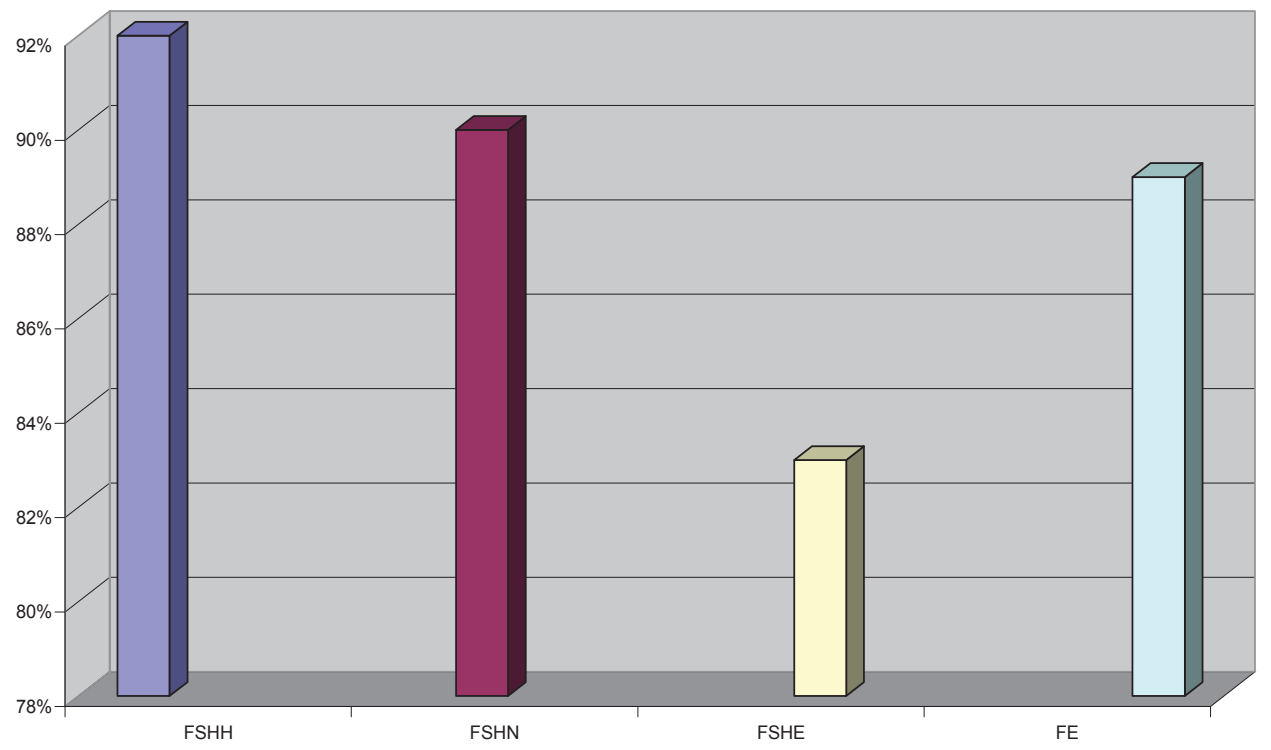

As to note-taking during the seminars, its function is less important. Evaluating all the replies, it results that the percentage for 'regularly' (50\%) and 'rarely (48\%) are more or less the same; $2 \%$ of the students reply 'never'. Where as considering the replies according to disciplines/courses the precentages change, from $63 \%$ for 'regularly' in FSHH, FSHN, FE to $30 \%$ in FSHE (see table/fig. 2) 
Fig. 2: Note-taking during seminars

Tab 2

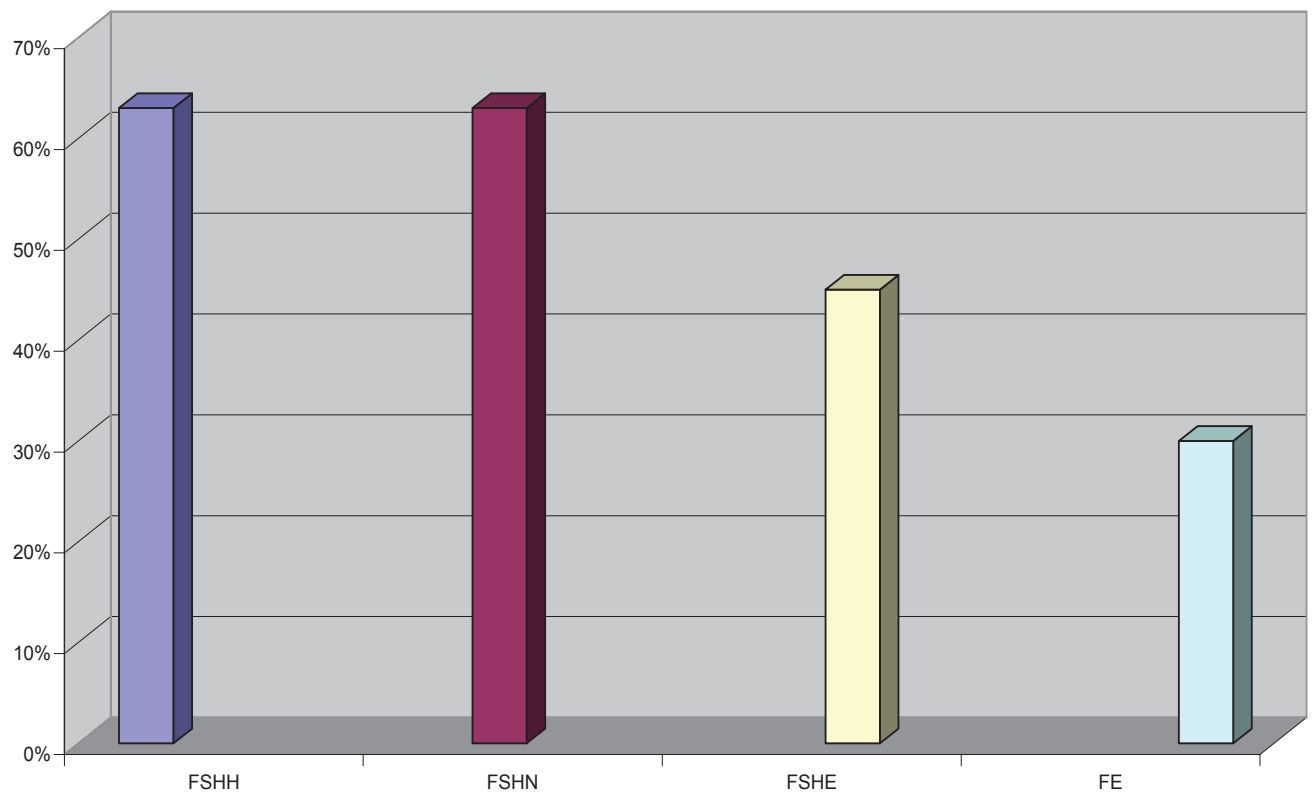

From the responses in the questionnaire, it was noticed that the efforts made by the university lecturers to convey the most necessary skills to the students for note-taking, are limited. Only $2 \%$ of the lecturers report for such kind of programs. A very interesting fact is also the evaluation of the responses for the question about the connection existing between scripts given by the lecturers and students' notes. Nearly one third of all the lecturers (64\%) use - 'always' or 'partly' - scripts designed by the lecturers themselves, which are given to the students.

\subsection{Protocol}

There was a question about 'protocols' in the questionnaire, how often the teachers use this type of text in university studies, and how much the students are able to design scientific protocols.

In university-wide view, it was noticed that protocols were never required during university studies, and there is not a single experience about this type of text.

\subsection{Summarizing}

There were some questions in the questionnaire for the text-type 'summarizing' (the key notes and main information). These questions had to do with the frequency of gathering information and the ability of the students to write this type of text. When lecturers were asked if the students use the technique of summarizing the main information, $24 \%$ of the lecturers asked, wrote that their students use this technique 'regularly', 59\% wrote 'very rarely', and $17 \%$ wrote 'never'.

Regarding the quality of writing $11 \%$ of the lecturers consider students' summaries 'good', $63 \%$ 'sufficient' ('average'-), and 26\% consider them 'poor'.

Concerning the pre-preparation of the students for this type of text, the questionnaire shows that the summarizing technique and drawing the main information is rarely practiced during university studies. Only $11 \%$ of the lecturers give positive reply. This is more or less the same with the use of note-taking. 


\subsection{Course assignment/Course paper}

Regarding the text 'course paper' the lecturers were asked if the students are required to write 'course papers' as a means of evaluation during their studies. They were asked 'how' and 'how much' the linguistic form influences in the assessment and evaluation of the course paper.

From the overall assessment and evaluation, it was noticed that the course paper type was not required in all disciplines/courses. Not taking into consideration the faculties, $62 \%$ of all the lecturers asked the students for submitting a coursepaper as an obligatory requirement for assessing and evaluating the students' performance in a certain subject/course.

The differences according to various disciplines/courses are of interest. The course papers in human and linguistic (philology) studies are very important and greatly used (93\%), in education sciences (92\%, and less in natural sciences (86\%), in economy sciences (79\%)

The linguistic form, generally, plays an important role in the assessment and evaluation of the written works. Among the linguistic factors, included in the questionnaire are: spelling, punctuation, general style and scientific style. In all the faculties/departments the four mentioned criteria are used more or less the same as far as frequency is concerned, and mostly in this combination: more frequently the scientific style (90\%), less punctuation (66\%), spelling and general style in the same frequency (80\%). (Fig. 3)/(Table 3)

The quality of presenting through a scientific high level language, plays a crucial role, especially in natural sciences (100\%), this style should be more important as compared to the general style of a certain written work. In human and philology sciences the right use of scientific language receives a high value (86\%), but it remains behind the general linguistic style (91\%). It gets the same great value in social sciences as well (90\%).

Fig.3: Linguistic factors

\begin{tabular}{|l|c|c|c|c|}
\hline & Spelling & Punctuation & General Style & Scientific Style \\
\hline Faculties & $80 \%$ & $66 \%$ & $80 \%$ & $90 \%$ \\
\hline
\end{tabular}

\section{Conclusions}

The results of this survey may give a valuable contribution for the development of the methodology/didactics/instructions of writing at university level. The qualification and training of students in these types of writing is necessary.

The form of scientific writing/course papers is a very important issue treated in this article, as well. It is also necessary to mention that this study has not taken into consideration all types of university texts. Other types and the way of teaching and practicing them might be object of another study in this field.

\section{References/Bibliography}

Moll, Melanie (2001) Protokollieren im Studium - eine wenig geübte Schreibtugend. In: Jahrbuch Deutsch als Fremdsprache 27. München: Iudicium

Kristo, Ema/ Stafa, Rezarta (2005) Wissenschaftliches Schreiben. Elbasan: Silver 